\title{
Frank Lestringant, André Gide l'inquiéteur. Tome I. Le ciel sur la terre ou l'inquiétude partagée 1869-1918
}

\section{Riccardo Benedettini}

\section{(2) OpenEdition}

1 Journals

\section{Edizione digitale}

URL: https://journals.openedition.org/studifrancesi/4803

DOI: $10.4000 /$ studifrancesi.4803

ISSN: 2421-5856

\section{Editore}

Rosenberg \& Sellier

\section{Edizione cartacea}

Data di pubblicazione: 1 avril 2012

Paginazione: 182

ISSN: 0039-2944

\section{Notizia bibliografica digitale}

Riccardo Benedettini, «Frank Lestringant, André Gide l'inquiéteur. Tome I. Le ciel sur la terre ou l'inquiétude partagée 1869-1918», Studi Francesi [Online], 166 (I | LVI) | 2012, online dal 30 novembre 2015,

consultato il 19 novembre 2021. URL: http://journals.openedition.org/studifrancesi/4803 ; DOI: https:// doi.org/10.4000/studifrancesi.4803

Questo documento è stato generato automaticamente il 19 novembre 2021.

\section{(c)}

Studi Francesi è distribuita con Licenza Creative Commons Attribuzione - Non commerciale - Non opere derivate 4.0 Internazionale. 


\title{
Frank Lestringant, André Gide l'inquiéteur. Tome I. Le ciel sur la terre ou l'inquiétude partagée 1869-1918
}

\author{
Riccardo Benedettini
}

\section{NOTIZIA}

FRANK LESTRINGANT, André Gide l'inquiéteur. Tome I. Le ciel sur la terre ou l'inquiétude partagée 1869-1918, Paris, Flammarion, 2011 («Grandes biographies»), pp. 1167.

1 Seguendo il metodo attento e documentato che lo ha reso noto soprattutto nel campo degli studi sul Rinascimento, Frank Lestringant presenta ora un libro che merita pienamente l'attenzione dei lettori di André Gide. Dopo aver indagato quali siano $\mathrm{i}$ limiti e il significato del termine «inquiéteur» creato da Gide, l'A. si propone di mostrare come l'omosessualità (nella forma della pederastia, vale a dire amore fra un adulto e un ragazzo) e l'appartenenza alla minoranza protestante costituiscano una particolare condizione di esigenza umanista da parte di uno scrittore emulo di Montaigne quanto lettore appassionato dei classici greci e soprattutto di Virgilio. Interessante è la sottile e complessa relazione tra il substrato riformato dell'autore, i suoi rapporti ambivalenti con la chiesa cattolica e un edonismo militante che lo portano ad inaugurare «un humanisme nouveau, radical, transgressif et libertaire» (p. 14), come leggiamo nella «Introduction» (pp. 9-19) intitolata «L'Homme-Gide». E di questo uomo-Gide Lestringant illustra quelle radici culturali e mentali che ne hanno fatto non il portavoce della società ma un suo dissidente, un avversario che ne discute $\mathrm{i}$ valori, il suo inquiéteur, appunto.

Questo primo volume, che esce in occasione del sessantesimo anniversario della morte di André Gide, abbraccia i primi cinquant'anni di vita dello scrittore ed è organizzato in diciotto capitoli, divisi dall'A. in quattro parti: «La Torpeur et l'éveil. 1869-1893» (pp.21-236), «La Conquête de l'immaturité ou l'usage des plaisirs. 1893-1902» 
(pp. 237-488), «Des ténèbres vers la lumière. 1903-1914» (pp. 489-780), «Le Ciel sur la terre. 1914-1918» (pp. 781-958). Dopo l'«Épilogue. Le tournant d'une vie (novembredécembre 1918)» (pp. 959-973) e la «Postface» (pp. 975-978), la cronistoria della vita di Gide è messa ulteriormente in rilievo nella «Chronologie (1869-1918)» (pp. 979-1008), la cui lettura aiuta nella ricostruzione dei fatti che permettono di evocare i nomi e i luoghi conosciuti dallo scrittore. La «Bibliographie sommaire» (pp. 1009-1032), il vasto apparato di «Notes» (pp. 1033-1140) e l'«Index» dei nomi (pp. 1141-1157) chiudono un lavoro che ci dà un'immagine "intima" della personalità di Gide: quella, per esempio, un po' sorprendente, del calvinista che non ama gli Ebrei ma che poi, ritrovata «son identité et son appartenance», è in grado di riconoscerne il comune gusto profondo «de la vérité et de la justice» (p.360). Leggendo le opere (compreso il Journal, la cui redazione accompagna lo scrittore fino agli ultimi giorni) e le correspondances di André Gide, così come le testimonianze dei contemporanei e la critica gidiana, Lestringant ne ricava il ritratto di un uomo che più volte ha saputo dare un nuovo orientamento alla propria esistenza e «dénoncer l'hypocrisie des valeurs sociales dominantes» (p. 972). 